\title{
Vaginal Birth After Repeated Cesrean Section: A Case Report
}

\author{
Necmi Arslan $^{1 *}$, Erkan Kibrisli ${ }^{1}$, Fatih Mehmet Findik ${ }^{2}$, Ahmet Yilmaz $^{1}$, Hamza Aslanhan $^{1}$
}

\begin{abstract}
Introduction: Cesarean section is a risky procedure. In most of the world, trial of vaginal birth after cesarean section (VBAC) is suggested and performed. In this case report, we aimed to show the possibility of vaginal labor in a patient who underwent repeated cesarean section and to review the risk of cesarean section.

Case Presentation: A female patient aged 32 years, who had cesarean section three times (gravida 5, parity 3, abortion 1) with 3 children, came to the delivery service when she went into final labor pain. On examination, it was seen that there was full dilatation of cervix and the fetus was in the vertex position. With episiotomy given and normal spontaneous vaginal delivery, a live baby boy of 3280 grams, $50 \mathrm{~cm}$ and Apgar score of 6-8 (at first and fifth minutes) was delivered. Having normal vital findings, the patient was discharged from the hospital on these conditions postpartum day 1.

Conclusion: Cesarean section increases maternal, prenatal mortality and morbidity. In health centers which have operative conditions, the option of normal spontaneous delivery should not be ignored for appropriate pregnant women.

Keywords: Cesarean section, Complication, Vaginal birth
\end{abstract}

\section{Introduction}

Being the most common surgical procedure worldwide in the practice of delivery, the rate of cesarean delivery has been increasing rapidly both in Turkey and in the world each passing day (1). Turkey has been one of the leading countries in terms of increase in cesarean section rate recently.The most common indications of cesarean section are previous cesarean section, labour dystocia, fetal distress and breech presentation.

It was found out that the increase in the rate of cesarean section is associated with the maternal complication risks. It is expected that the rate of maternal complication risk will increase as those rates increase (2). Cesarean section is a risky procedure. During the procedure or afterwards, there may be observed anaesthesia risks, bleeding, need for blood transfusion, adjacent organ damages, emboli, increased neonatal morbidity and injury, neonatal respiratory distress syndrome, infections (endometritis, wound infections), maternal psychological problems, repeated cesarean section and related risks (placenta previa, uterine rupture, intra-abdominal adhesion) (3).

In most of the world, trial of vaginal birth after cesarean section (VBAC) is suggested and performed. This rate is $19.9 \%$ in the United States and $53 \%$ in Sweden. Studies have shown that the rate of success could reach up to $60 \%-90 \%$ by choosing the appropriate candidates (4). In this manuscript, we aimed to draw attention to the risk of cesarean section and to show the possibility of alternative routes in a case that has undergone repeated cesarean section.

\section{Case Presentation}

A female patient aged 32 years who had undergone cesarean section three times (gravida 5 , parity 3 , abortion 1 ) and had 3 children, came to the delivery service when she went into final labour. On examination, it was seen that there was full dilatation and the fetus was in the vertex position. Ultrasonography could not be done. The patient was followed up in the operating room. By giving an episiotomy and normal spontaneous vaginal delivery, a live baby boy of 3280 grams, $50 \mathrm{~cm}$ and Apgar score of 6-8 at first and fifth minutes was delivered. The episiotomy was fixed. Postpartum oxytocin intravenous infusion of the patient was followed.

In laboratory tests, blood type, white blood cell, hematocrit, hemoglobin and red blood cell was found respectively as ARh (+), $11.21 \mathrm{~K} / \mathrm{uL}, 28.01 \%, 9.48 \mathrm{~g} / \mathrm{dl}, 3.47 \mathrm{M} / \mathrm{uL}$. In postpartum follow-ups, it was observed that the uterus was involuted on abdominal examination. There was no peculiarity on vaginal examination. Uterus contours were regular in ultrasonography and there was no free fluid in abdomen. On the first postpartum day, hemoglobin was $8.71 \mathrm{~g} / \mathrm{dl}$ and hematocrit was $25.64 \%$. Having normal vital findings, the patient was discharged from the hospital on the second postpartum day.

\section{Discussion}

Cesarean section enhances maternal, prenatal mortality

Received 15 January 2016, Accepted 21 May 2016, Available online 8 June 2016

${ }^{1}$ Department of Family Medicine, Faculty of Medicine, University of Dicle, Diyarbakir, Turkey. ${ }^{2}$ Department of Obstetrics and Gynecology, Faculty of Medicine, University of Dicle, Diyarbakir, Turkey.

*Corresponding author: Necmi Arslan, Department of Family Medicine, Faculty of Medicine, University of Dicle, Diyarbakir, Turkey. Tel: +904122411000; Email: narslan23@hotmail.com 
and morbidity. Comparing vaginal delivery and cesarean section, it was seen that the infection risk of cesarean section is $5-20$ times more (2). While maternal death is less than $1 / 10000$ after vaginal delivery, death risk based on cesarean section is around $1 / 2500$, which is 4 times more than regular delivery (3). Since the dictum "once cesarean, always cesarean" asserted by Cragin in 1916, the rate of cesarean section has enhanced gradually and one of the most common causes of cesarean indication has been the elective cesarean which is carried out after the previous cesarean (5).

In time, studies based on the fact that Cragin's notion is not absolutely right and VBAC is possible have been performed (6). The World Health Organization (WHO) has suggested withdrawing the rate of cesarean section to an optimal rate of $15 \%$ and that the increased maternal mortality and morbidity based on increased cesarean section rate could be decreased (7). Along with this approach, trial of normal vaginal delivery after cesarean section was started to be recommended in order to reduce cesarean rates and related complications, moreover, oriented studies were initiated.

In a study by Rosen et al, considering elective cesarean in patients who tried VBAC (excluding the fetal deaths before activity, fetuses less than $750 \mathrm{~g}$ and congenital anomalies not accorded with life), there could not be found significant difference between two groups in terms of mortality (5). In the study by McMahon et al, cases of VBAC and cesarean were compared and it was found out that major complications (hysterectomy, uterine rupture and operative damage) are 1.8 times more common in cesarean section (8).

Uterine rupture is a full-thickness separation of the uterine wall and the overlying serosa. It is a visible or palpable anatomic finding, not a health consequence and is an important reason of maternal and perinatal morbidity and mortality. Uterine rupture is directly associated with vaginal delivery after cesarean section and divided into two groups as complete and incomplete. In complete uterine rupture, uterine wall is totally ruptured and uterine cavity (9). With repeated cesarean deliveries, especially, the frequency of placenta adhesion anomalies enhances. In many studies on the risk of maternal mortality for VBAC, it has been shown that the maternal mortality rate in cases in which VBAC was tried (3.8 in 100000 patients) was statistically less than the maternal mortality rate in repeated elective cesarean delivery (13.4 in 100000 patients) (10). There was less venous thrombosis in patients who had VBAC after one cesarean delivery as compared to patients who had VBAC after two or more cesarean sections (0.04\%, $0.1 \%$ and $0.1 \%$, respectively) (11).

Cesarean section procedure is a risk factor to abnormal placentation (placenta previa, placenta accreta, increta, percreta) in the following pregnancies. Abnormal placentation is in a close relation with both fetal mortality and morbidity. Preterm activity, emergency cesarean, need for hysterectomy, blood transfusion, other intraoperative organ damages and intensive care for newborn infant are important problems for those patients. It is suggested to decrease the number of the cesarean sections in order to avoid those problems which could end up with life threating results most of the time. At that point, VBAC is an important alternative $(2,12)$. Problems which could be seen in patients who attempt VBAC are under the influence of many factors such as education level, age, ethnicity, weight of the patient and the baby, time of delivery, the week of the pregnancy and the position of the fetal head (13).

In the health centers which have operative conditions, the option of normal spontaneous delivery should not be ignored for the appropriate pregnant women who have had cesarean section beforehand in order to reduce the increased cesarean section rate and morbidity, mortality results related to cesarean section as well as to shorten the duration of hospital stay and lower the costs.

\section{Ethical Issues}

The authors have obtained permission before using patient data and images.

\section{Conflict of Interests}

The authors declared that there is no conflict of interests regarding the publication of this article.

\section{Financial Support}

The authors declared that this study had received no financial support.

\section{Acknowledgments}

None to be declared.

\section{References}

1. Jackson NV, Irvine LM. The influence of maternal request on the elective cesarean section rate. J Obstet Gynaecol. 1998;18(2):115-119. doi:10.1080/01443619867812.

2. Silver RM, Landon MB, Rouse DJ, et al. Maternal morbidity associated with multiple repeat cesarean deliveries. Obstet Gynecol. 2006;107(6):1226-1232. doi:10.1097/01. AOG.0000219750.79480.84.

3. İğde Artıran F. Sezaryen sonrası normal vaginal doğum. STED. 2004;13:137-40.

4. Gungor ES, Ertas E, Moroy P, Celen S, Danisman N, Mollamahmutoglu L. Vaginal birth after cesarean. Is it safety? Perinatal J. 2005;13(4):208-212.

5. Rosen MG, Dickinson JC, Westhoff CL. Vaginal birth after cesarean: a meta-analysis of morbidity and mortality. Obstet Gynecol. 1991;77(3):465-470.

6. Childbirth C. Report of the NICHD Task Force on Cesarean Childbirth (NIH publ 82-2067). Bethesda, MD: National Institutes of Health, US Dept of Health and Human Services; 1981.

7. Appropriate technology for birth. Lancet. 1985;2(8452):436437.

8. McMahon MJ, Luther ER, Bowes WA Jr, Olshan AF. Comparison of a trial of labor with an elective second cesarean section. N Engl J Med. 1996;335(10):689-695. doi: 10.1056/nejm199609053351001.

9. Kurdoglu Z, Kurdoglu M. The risk of uterine rupture in labour induction of women with previous cesarean delivery. 
Crescent J Med Biol Sci. 2016;3(1):8-13.

10. Flamm BL, Goings JR, Liu Y, Wolde-Tsadik G. Elective repeat cesarean delivery versus trial of labor: a prospective multi center study. Obstet Gynecol. 1994;83(6):927-932.

11. Landon MB, Hauth JC, Leveno KJ, Spong CY, Leindecker $\mathrm{S}$, Vaener MW, et al. Maternal and perinatal outcomes associated with a trial of labor after prior cesarean delivery. N Engl J Med. 2004;351:2581-2589.

12. Juntunen K, Makarainen L, Kirkinen P. Outcome after a high number (4-10) of repeated caesarean sections. BJOG 2004;111(6):561-63. doi:10.1111/j.1471-0528.2004.00154.x.

13. Schoorel EN, Kuijk SM, Melman S, Nijhuis JG, Smits LJ, Aardenburg R, et al. Vaginal birth after a caesarean section: the development of a Western European populationbased prediction model for deliveries at term. BJOG. 2014;121(2):194-201. doi:10.1111/1471-0528.12539.

Copyright (c) 2016 The Author(s); This is an open-access article distributed under the terms of the Creative Commons Attribution License (http://creativecommons.org/licenses/by/4.0), which permits unrestricted use, distribution, and reproduction in any medium, provided the original work is properly cited. 